UNIVERSITÀ CATTOLICA DEL SACRO CUORE

Dipartimento di Economia e Finanza

\author{
Working Paper Series
}

Strategic Location Choice under Dynamic

Oligopolistic Competition and Spillovers

Luca Colombo

Herbert Dawid

Working Paper $\mathbf{n} .1$

November 2013

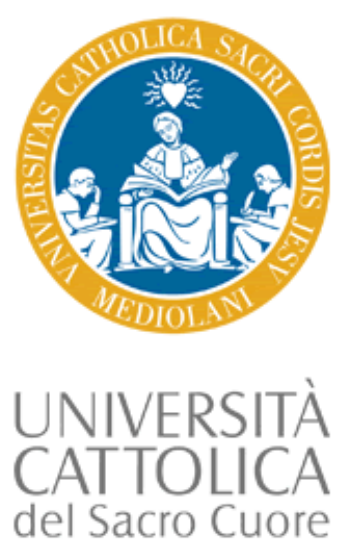




\title{
Strategic Location Choice under Dynamic Oligopolistic Competition and Spillovers
}

\author{
Luca Colombo \\ Università Cattolica del Sacro Cuore \\ Herbert Dawid \\ Bielefeld University
}

\author{
Working Paper n. 1 \\ November 2013 \\ Dipartimento di Economia e Finanza \\ Università Cattolica del Sacro Cuore \\ Largo Gemelli 1 - 20123 Milano - Italy \\ tel: +39.02.7234.2976 - fax: +39.02.7234.2781 \\ e-mail: dip.economiaefinanza@unicatt.it
}

The Working Paper Series promotes the circulation of research results produced by the members and affiliates of the Dipartimento di Economia e Finanza, with the aim of encouraging their dissemination and discussion. Results may be in a preliminary or advanced stage. The Dipartimento di Economia e Finanza is part of the Dipartimenti e Istituti di Scienze Economiche (DISCE) of the Università Cattolica del Sacro Cuore. 


\title{
Strategic Location Choice under Dynamic Oligopolistic Competition and Spillovers*
}

\author{
Luca Colombo ${ }^{\dagger} \quad$ Herbert Dawid ${ }^{\ddagger}$
}

October 2013

\begin{abstract}
This paper investigates firms' optimal location choices explicitly accounting for the role of inwards and outwards knowledge spillovers in a dynamic Cournot oligopoly with firms that are heterogeneous in their ability to carry out cost-reducing R\&D. Firms can either locate in an industrial cluster or in isolation. Technological spillovers are exchanged between the firms in the cluster. It is shown that a technological leader has an incentive to locate in isolation only if her advantage exceeds a certain threshold, which is increasing in firms' discount rate, in industry dispersion, and in the intensity of knowledge spillovers. Scenarios are identified where although it is optimal for the technological leader to locate in isolation, from a welfare perspective it would be desirable that she locates in the cluster.
\end{abstract}

Keywords: Location Choice, Knowledge Spillovers, Technological Leadership, Markovperfect Equilibrium

JEL-Code: L13, C73, O31, R12

\section{Introduction}

A rich literature has investigated a variety of factors affecting the location choices of firms, ranging from the proximity to important sales markets to the availability and costs of relevant inputs $^{1}$, from the benefits of an active market for skilled labor (see e.g. Almazan et al., 2007),

*Financial support under COST Action IS1104 "The EU in the new economic complex geography: models, tools and policy evaluation" is gratefully acknowledged.

${ }^{\dagger}$ Università Cattolica del Sacro Cuore, Department of Economics and Finance, Largo Gemelli 1, I-20123 Milano, Italy. E-mail: lucava.colombo@unicatt.it

${ }^{\ddagger}$ Bielefeld University, P.O. Box 100131, D-33501 Bielefeld, Germany. E-mail: hdawid@wiwi.uni-bielefeld.de.

${ }^{1}$ In the New Economic Geography literature, transportation costs play a crucial rule in shaping the level of agglomeration in the economy; see e.g. Krugman (1991), Krugman and Venables (1995), or Fujita et al. (1999), Fujita and Thisse (2002) and Ottaviano and Thisse (2004) for comprehensive reviews on these issues. 
to local regulatory and institutional conditions (e.g. Lee and Mansfield (1996), Henisz (2000), Busse and Hefeker (2007), De Beule and Duanmu (2012)).

Knowledge is widely recognized as an important source of competitive edge, especially for technologically advanced firms. As it is well known from the innovation literature since at least Marshall (1890), one natural way to acquire additional knowledge - especially in technologically advanced industries - is through knowledge spillovers across organizational boundaries, which are largely facilitated by proximity. As knowledge is often tacit and localized, geographical proximity is key for its transfer ${ }^{2}$. Therefore, the consideration of (potential) knowledge flows and the technological spillovers they induce should play an important role for firms' strategic location decisions, in addition to the factors traditionally highlighted by the localization literature (this is even more true in a world where the role of transportation cost is declining, see e.g. Glaeser and Kohlhase, 2004). Consistent with this view, in an important empirical contribution focusing on first-time market entrants into the United States between 1985 and 1994, Alcácer and Chung (2007) find that less technologically advanced firms favor locations with high levels of industrial innovative activity, while technologically advanced firms avoid economic areas with high industrial activity. In interpreting these empirical findings, they argue that firms consider both the gains from inwards spillovers (i.e. the possibility of knowledge sourcing from the other firms in a cluster) and the costs of outwards spillovers (benefiting competitors) when assessing their location strategies, which induces leading firms to avoid competitors by steering away from industrial activity.

A rich literature has documented the existence of knowledge spillovers in local agglomerations like clusters (e.g. Griliches (1992), Jaffe et al. (1993)), mainly interpreting them as positive externalities that should lead to fast dynamics of knowledge generation. In this perspective, clusters are seen as unambiguously attractive for firms (as noted, e.g., by Head et al., 1995). The role of outwards spillovers - or better that of net spillovers, defined as the difference between inwards and outwards spillovers - has however been neglected in most of the literature, and it is therefore an important contribution of the paper by Alcácer and Chung (2007) ${ }^{3}$. In subsequent work based on Italian firm-level data Mariotti et al. (2010) qualitatively confirm the insights by Alcácer and Chung (2007). They show that knowledge spillovers positively impact the agglomeration of Multi-National Enterprises (MNEs) with other MNEs, whereas agglomeration with domestic firms is negatively affected by the existence of knowledge spillovers. Given that on average MNEs are technologically more advanced than domestic firms, Mariotti et al. (2010)

\footnotetext{
${ }^{2}$ As reported in Almazan et al. (2007, footnote 2, p. 1306), Manes and Andrews (1994, p.120) - discussing Microsoft's location decision - state that "Paul Allen increasingly argued for a move back to familiar Seattle turf. Hiring might be simpler in Silicon Valley, but keeping employees would clearly be harder, a major consideration in a business where the primary assets walk out the door every night".

${ }^{3}$ Combes and Duranton (2006) investigate in a duopoly game the trade-off between the outwards spillovers stemming from labor poaching and the inwards spillovers induced by labor pooling when firms cluster in the same local labor market.
} 
interpret these observations suggesting that MNEs are afraid of technological leakages when agglomerating with domestic firms.

When accounting for the dynamic effects of outwards spillovers as well, the location choice of firms becomes a non-trivial one. Indeed, technological leaders, being primarily concerned with the long run effects of outwards spillovers, may end up locating in isolation rather than in clusters, as documented empirically by Alcácer and Chung (2007). The observation that technological leaders make systematically different location choices than technological laggards has been further reinforced by Belderbos et al. (2008a), who show in an empirical study that leaders are more attracted than laggards to countries with better intellectual property rights (IPRs) protection.

Somewhat surprisingly, despite the available empirical evidence highlighted above, the analysis of the effects of knowledge spillovers on the location choices - clustering with competitors vs. isolation - of firms maximizing their discounted streams of future profits has attracted relatively little attention by the theoretical literature. In this paper, we analyze the issue in a differential game framework, by taking explicitly into account both the strategic and the dynamic implications of firms' location choices in an economy characterized by the presence of inwards and outwards knowledge spillovers ${ }^{4}$. In particular, we study under which circumstances it is optimal for a technological leader to locate outside an industry cluster with rich R\&D activity. Furthermore, we also characterize how the incentives to locate in the cluster or in isolation are affected by the intensity of knowledge spillovers in the cluster, by the degree of competition in the industry, and by firms' discount rate. Finally, we look at the long run effects of the technological leader's location decision on the overall industry profits and on consumers' surplus (i.e. on social welfare), which allows us to make normative statements that can be used to inspire the design of policy measures.

To address these research questions we characterize the Markov-perfect Equilibria of a differential game where $n$ firms producing a homogeneous good compete on a common (world) market by choosing at each point in time $t$ an output quantity. The production costs of firms depend negatively on their knowledge stock, which can be increased by R\&D investment. There is a single industrial cluster in the industry and firms located in it receive spillovers proportional to the total size of the knowledge stock of all firms belonging to the cluster. Each firm is either located in the industrial cluster or in isolation, and firms not located in the cluster neither receive spillovers nor produce outwards spillovers to any of their competitors. As the fist step of the analysis, we characterize the feedback strategies of the firms in the cluster and in isolation with respect to their $R \& D$ investments in a Markov perfect equilibrium of the game for an arbitrary location pattern of firms. Relying on numerical analysis we then study the incentives

\footnotetext{
${ }^{4}$ Although we focus essentially on the impact of spillovers on firms' location decisions, we acknowledge that several other factors - whose effects have already been carefully investigated by the existing literature - play a role, and that firms' decisions will eventually reflect these factors as well.
} 
of firms to locate in the cluster, based on the difference between the value functions under the Markov-perfect Equilibrium of the differential game for the two possible location choices. We assume that one firm - the technological leader - is structurally more efficient in carrying out $R \& D$ than her competitors, and we focus our attention on her location choice.

We show that the technological leader chooses to locate in isolation if and only if her cost advantage over the competitors is sufficiently large. Two main effects govern the dynamics of profits establishing whether the leader locates in the industrial cluster or in isolation. Initially, the leader benefits from locating in the cluster, due to a lower investment in $R \& D$ relative to the case in which she locates in isolation. The lower investment is a consequence of the leader anticipating that, when she locates in the cluster, her R\&D efforts reduce the future costs of competitors, which in turn reduces her incentives to invest in the first place. However, this investment effect is contrasted in the long run by the faster catching-up of the followers when the leader locates in the cluster, due to the stronger outwards spillovers that her presence generates. This leads to a lower market share for the leader compared to the case in which she locates in isolation, an effect that in the long run dominates the effect on $R \& D$ investment highlighted above. Hence, in the long run the technological leader is better off locating in isolation. The combination of the short run investment effect and the long run market share effect determines whether, for given intensity of knowledge spillovers, the leader ends up locating in the core or in isolation.

The threshold at which the location choice of the technological leader changes between cluster and isolation is shown to be increasing in the discount rate of firms (as well as in the knowledge depreciation rate), suggesting that the incentives for the leader to join the industry cluster are larger the more 'myopic' she is. Furthermore, the threshold is also increasing in the number of competitors operating in the market and in the intensity of knowledge spillovers, so that the incentives of the leader to locate in the cluster are higher the more dispersed the industry is and the more important knowledge spillovers are.

The leader's location choice problem has interesting implications also when looking at total industry performance and welfare. Indeed, our numerical analysis shows that both total industry profits and welfare may be systematically larger if the leader locates in the cluster rather than in isolation. Hence, locating in isolation can be the optimal choice in the leader's perspective, but an inefficient one from the social point of view. The inefficiency result stems from the fact that the leader's choice to locate in the cluster strengthens competition, implying a reduction in market prices that has a positive effect on consumers' surplus, which is not taken into account by the leader.

One possible criticism to the analysis summarized above rests in the specific definition of technological leadership we adopt, which endows the leader with a higher efficiency in performing $R \& D$ activities with respect to the other firms in the industry. Although such a definition is appropriate when focusing on established oligopoly markets in which leadership is typically 
based on a structural cost advantage, it does not capture the situations in which a firm only has an initial knowledge advantage with respect to its competitors, as it is often the case for market pioneers in newly established sub-markets within an industry.

Exploring this possibility leads to different insights with respect to those highlighted above for the case in which the technological leader has a structural advantage. In fact, although it remains true also for the initial advantage case that the technological leader has an incentive to locate in isolation only if her advantage is above a threshold, the dynamics of both the difference in instantaneous profits and that in knowledge stocks under the two location choices are strikingly different. While in the structural advantage scenario both the long run profits and the knowledge stock of the leader are lower if she joins the cluster than if she locates in isolation, exactly the opposite occurs when the leader has an initial R\&D advantage only. Intuitively, this difference is driven by the fact that, when the leader has a structural advantage and she locates in the cluster, the wedge between outwards and inwards spillovers is systematically larger for her than for all other firms in the cluster, meaning that she implicitly cross-subsidizes her competitors. Conversely, when the leader benefits from a temporary initial advantage only, in the long run the balance of outwards and inwards spillovers is the same for both the leader and her competitors, and by locating in the cluster the leader can benefit from the larger externalities that emerge there compared to isolation. The same qualitative argument helps explaining the negative relationship between the leader's location threshold (cluster vs. isolation) and the discount rate of firms in the initial advantage case, again opposite to what is found for the structural advantage case. The effects of the leader's location choice on total industry profits and consumers' surplus are instead the same under both the initial advantage and the structural advantage scenarios, as - in both cases - they are mainly driven by the increase in industry competition occurring when the leader joins the cluster.

The rest of the paper is organized as follows. We briefly review the pertinent literature in Section 2 below. Section 3 illustrates the benchmark model, while Section 4 characterizes the Markov Perfect Equilibrium and proves the existence of a globally stable steady state. Section 5 examines the incentives of the technological leader to locate in the industry cluster rather than in isolation, and it investigates how her location choice is affected by the intensity of knowledge spillovers, industry competition and discounting. Section 6 then extends the analysis to the case in which technological leadership is determined by the existence of an initial knowledge advantage with respect to competitors, rather than by a structural advantage. Section 7 concludes. Auxiliary figures are provided in an Appendix.

\section{Related Literature}

Despite the empirical literature cited in the Introduction has documented the impact of knowledge spillovers on firms' location choices in a variety of different environments (see e.g. Head et 
al. (1995), Audretsch and Feldman (1996), Alcácer and Chung (2007), Belderbos et al. (2008a), and Alcácer and Zhao (2012)), the effects of knowledge flows on firms' location choices has received relatively little attention in the theoretical literature, but for a few notable exceptions.

Gersbach and Schmutzler (1999) focus on a two stage Bertrand duopoly model in which firms first decide on the location of both production and (cost-reducing) innovative activities in the presence of internal and external knowledge spillovers and then compete with respect to the product price ${ }^{5}$. Similar to us, their analysis shows that firms' location decisions are significantly affected by knowledge spillovers, which shape the geography of production and innovation. Differently from us, however, their setup is static, so that they are unable to investigate the effects of the dynamics of knowledge flows and profits on firms' location choices, and to capture the potential trade-offs between the short and long run implications of firms' location decisions ${ }^{6}$.

Knowledge spillovers play a crucial role also in Piga and Poyago-Theotoky (2005), who consider a three-stage duopoly game in which firms choose where to locate, as well as qualityenhancing R\&D efforts and product prices, in the presence of endogenous spillovers the extent of which is decreasing in firms' distance. The flavor of their paper is, however, very different from ours in that they stress the role of transportation costs (also interpreted as product differentiation) for both firms' location choices and R\&D efforts, which instead plays no role at all in our model.

A few papers have concentrated on the role of spillovers in the strategic location of R\&D by multinational firms ${ }^{7}$. Belderbos et al. (2008b) - building on the model of spillovers introduced in Gersbach and Schmutzler (1999) - study the strategic interactions between the R\&D location decisions of two multinational firms competing both abroad and in their home markets, focusing on the different incentives in the R\&D location decisions faced by a technological leader and by a technological laggard. They show that the equilibrium share of R\&D located abroad depends on the extent of inwards and outwards spillovers, on the intensity of competition in the product market, on the technological gap between the leader and the laggard, as well as on the efficiency of international knowledge transfers. Their contribution is related to ours in that some of the key channels they highlight play an important role in our setup as well. Nonetheless, the research question they address is entirely different from ours. Furthermore, also the framework

\footnotetext{
${ }^{5}$ In a more recent contribution, Gersbach and Schmutzler (2011) address a related issue and focus on the choices of locations for both production and R\&D activities by multinational firms in the presence of knowledge sourcing, treating foreign direct investments and R\&D locations as jointly endogenous.

${ }^{6}$ Besides for the type of competition in the product market - Cournot vs. Bertrand -, the setups of the two papers also differ in that we do not distinguish between the location of production and that of innovative activities, while Gersbach and Schmutzler (1999) do.

${ }^{7}$ Interestingly, a large fraction of private sector R\&D is performed by multinational firms (more than two thirds out of a total of $\$ 450$ billion in 2002, according to UNCTAD (2005)), which also show an increasing tendency to relocate $\mathrm{R} \& \mathrm{D}$ activities offshore.
} 
developed by Belderbos et al. (2008b) is static, whereas we develop a dynamic game-theoretic framework that, as already noted above, allows us to fully investigate both the short and long run effects of firms' location decisions.

The R\&D location decisions of multinational firms in the presence of spillovers have also been investigated by Petit and Sanna-Randaccio (2000) and Ekholm and Hakkala (2007). However, besides relying on static models, the specific research questions asked by these papers are quite far from those we ask. In fact, while we look at how knowledge spillovers influence the location choices of firms, Petit and Sanna-Randaccio (2000) focus on the effects of R\&D activities on the international expansion modes of firms. Ekholm and Hakkala (2007), instead, focus on the key drivers of multinational firms' agglomeration, showing that the main driving force behind firms' location choices is the return to skilled labor - which plays no role here. In their model, spillovers are essentially seen as an element favoring the agglomeration of $R \& D$ activities, while here they take center stage as the main determinant of firms' location choices.

Alcácer et al. (2013) investigate multinational enterprises' location choices across time and markets under different learning scenarios tying decreases in firms' marginal costs to cumulative production. They show that in oligopolistic industries (the typical case when focusing on MNE), firms' location choices are made strategically in order to foster their competitive advantage and to undermine the growth potential of competitors within an industry - deterring them from entering and entrenching in key markets. The key novelty of Alcácer et al. (2013) contribution is the fact that they develop a game-theoretic sequential model of location choice, whereby heterogeneous firms competing à la Cournot in product markets take decisions about multiple locations in a multi-period framework that affect the competitive conditions of the industry. Although the strategic reasoning behind firms' location choices in Alcácer et al. (2013) is different from the one we consider here (they stress the effect of firms' choices on an industry competitive environment, while we highlight the impact of knowledge externalities on firms' choices), the two papers are nonetheless related in that - albeit in entirely different ways both consider the dynamic effects of strategic interactions on the geographic expansion of firms, which so far received little attention in the literature.

Bischi and Lamantia (2012a, 2012b) provide a dynamic analysis of firms' choices of R\&D effort in a Cournot oligopoly market where firms are partitioned in several groups, which may also be interpreted as clusters. Firms completely share R\&D results with a selected set of competitors in their group and exchange (lower intensity) spillovers also with all other firms in the group. Bischi and Lamantia (2012a, 2012b) characterize the steady state values of R\&D effort under different network structures and also consider the local stability properties of these steady states, as well as the characteristics of the global dynamics. Contrary to our approach, however, the partitioning of firms into the groups and also the set of ties within groups is taken as given, such that location decisions are not considered. Also, Bischi and Lamantia (2012a, 2012b) assume that firms are myopic and adjust their actions based on a gradient-type dynamics, 
whereas we consider firms that determine their decisions by intertemporal optimization of their future (discounted) profit stream.

Finally, Almazan et al. (2007) look at the location choices of firms in the absence of transportation costs but in the presence of an active labor market. The key idea is that the decision to locate in a cluster rather than in isolation has to do with the competitiveness of the market for skilled labor. As it is costly for a worker to relocate, a firm in isolation can become a monopsonist in the market for skilled labor while, for firms in a cluster, workers can offer their skills in a competitive labor market. Although Almazan et al. (2007) develop a theory of firms' location choices based on the creation and allocation of human capital ${ }^{8}$, their argument is clearly related to ours to the extent that knowledge is partly tacit and embedded in skilled workers, so that the intensity of spillovers depends on the competitiveness of the labor market.

\section{The Model}

We consider a dynamic Cournot oligopoly model of an industry consisting of $n$ firms offering a homogeneous good. At each point in time $t \geq 0$ firms simultaneously choose quantities. There is a representative consumer, whose preferences are described by a quadratic Dixit-Stiglitz utility function yielding an inverse demand function of the form

$$
p(t)=a-b \sum_{j=1}^{n} q_{j}(t), a, b>0,
$$

where $q_{j}(t) \geq 0$ denotes the quantity of firm $j$ and $p(t)$ the price of the good at time $t$.

We assume that all firms have constant marginal costs and that the level of marginal costs of firm $i$ at time $t, c_{i}(t)$, depends on its stock of (cost-reducing) knowledge $k_{i}(t)$ at time $t$ in a linear way, i.e.

$$
c_{i}(t)=\bar{c}-\gamma k_{i}(t), \bar{c}, \gamma>0 .
$$

This formulation implies that in the absence of any cost-reducing knowledge all firms have identical marginal costs. To avoid negative marginal costs, we add the state constraint

$$
k_{i}(t) \leq \frac{\bar{c}}{\gamma} \quad i=1, \ldots, n
$$

At time $t=0$ each firm chooses where to locate and this decision determines whether the firm is exposed to inwards and outwards knowledge spillovers, which affect the dynamics of its own knowledge stock as well as that of its competitors. In particular, we assume that there exists a single industrial cluster and that all firms in the cluster receive spillovers from all the other firms in the cluster and transfer (a fraction of) their own knowledge to the other firms in the cluster. Alternatively, a firm can decide to locate in isolation, which implies that no

\footnotetext{
${ }^{8}$ They argue that the choice of a firm to locate in a cluster or in isolation is influenced by the extent to which training costs are borne by firms versus employees.
} 
knowledge flows to or from this firm arise. For simplicity, we assume that no direct costs are associated with either of the two location choices. Furthermore, no relocation is possible at any point in time $t>0^{9}$. Formally, each firm chooses its location $l_{i} \in\{C, I\}$ at $t=0$. We denote with $N_{C} \subseteq\{1, \ldots, n\}$ the set of firms in the cluster, with $\left|N_{C}\right|=n_{C} \leq n$. Analogously, $N_{I}$ is the set of firms that choose to locate in isolation.

The knowledge stock of firm $i$ is increased by its $\mathrm{R} \& \mathrm{D}$ effort, $x_{i}$, and decreased by knowledge depreciation, at the rate $\delta>0$, assumed to be identical for all firms. Furthermore, firms in the cluster benefit from incoming spillovers, which are assumed to be proportional to the aggregate knowledge of all other firms in the cluster. Formally, we have

$$
\dot{k}_{i}(t)=\left\{\begin{array}{ll}
x_{i}+\beta \sum_{j \in N_{C} \backslash\{i\}} k_{j}-\delta k_{i} & l_{i}=C \\
x_{i}-\delta k_{i} & l_{i}=I
\end{array} .\right.
$$

The parameter $\beta>0$ measures the intensity of knowledge flows in the cluster. This simple formulation captures the existence of knowledge spillovers in agglomerations, which is well established empirically (see e.g. Jaffe et al. (1993), Saxenian (1994)). Note further that, under this formulation, the positive externality induced by the entry of a firm into the cluster is larger the more knowledge this firm has.

$\mathrm{R} \& \mathrm{D}$ effort is associated with the quadratic cost function

$$
g\left(x_{i}\right)=\frac{\eta_{i}}{2} x_{i}^{2}
$$

for all firms $i=1, \ldots, n$. Our key focus is on the optimal location choice of a technological leader. For most of the paper, we capture the technological leadership of a firm in terms of the differences between its R\&D cost function and those of competitors. In particular, we assume that all firms except for firm 1 have identical R\&D cost functions (i.e. $\eta_{i}=\eta, i=2, . ., n$ ). Without loss of generality, we let firm 1 be the technological leader, assuming that she is able to generate new knowledge at a lower cost than competitors, which we label as laggards throughout the paper. Formally, we have that $\eta_{1}<\eta$. This formulation captures, in a reduced form, scenarios where one firm is able to carry out $R \& D$ and to produce new knowledge more efficiently than its competitors. Although we do not discuss in details the possible sources of such technological leadership, we point out that heterogeneities of this kind have been identified in empirical work and that our formulation is consistent, e.g., with the empirical approach of Alcacer and Chung (2007), who label as technological leaders those firms that have the highest R\&D intensity. It is straightforward to see that in our setting, ceteris paribus, the firm with the lowest value of $\eta_{i}$ - in our case firm 1 - based on the optimal choice of R\&D effort has the highest R\&D intensity.

\footnotetext{
${ }^{9}$ This assumption is mainly made for reasons of tractability. In any case, relocation is associated with large transaction costs making it a long run decision.
} 
Firms maximize their discounted profits, where the choice variables are the initial location choice, $l_{i}$, as well as the R\&D effort, $x_{i}(t)$, and the output quantity, $q_{i}(t)$, at each point in time $t \geq 0$. More precisely, the objective of firm $i$ is to maximize

$$
J_{i}=\int_{0}^{\infty} e^{-r t}\left[\left(p(t)-c_{i}(t)\right) q_{i}(t)-g\left(x_{i}(t)\right)\right] d t,
$$

subject to $(1),(2),(4)$ the constraints $(3),\left(q_{i}(t), x_{i}(t)\right) \geq 0$, and

$$
k_{i}(0)=k_{i}^{i n i}
$$

for a given distribution of initial knowledge $\left(k_{1}^{i n i}, \ldots, k_{n}^{i n i}\right)$.

\section{Equilibrium Analysis}

We investigate firms' optimal location choices by comparing the value functions arising from the differential game (5) for different location choices. We assume that firms use Markovian feedback strategies when playing the differential game. Standard arguments establish that the quantity choices of the firms have no intertemporal effects, and hence at each point in time firms choose Cournot quantities given the current profile of marginal costs. Concerning R\&D investments, a Markovian feedback strategy of firm $i$ has the form

$$
X_{i}\left(k_{1}, . ., k_{n}\right), i=1, . ., n \text { with } X_{i}:\left[0, \frac{\bar{c}}{\gamma}\right]^{n} \rightarrow[0, \infty) .
$$

Given that our differential game is linear-quadratic, Markov-perfect equilibria (MPE) can in principle be characterized using standard methods and assuming quadratic value functions for all players (see e.g. Dockner et al. (2000)). However, the fact that the state-space of the game has dimension $n$ makes the analysis numerically difficult for large values of $n$, since the number of equations that need to be solved for characterizing the MPE is of the order $n^{3}$. However, given the symmetry between all laggard firms, it is intuitive that there should exist a Markov-perfect equilibrium at which all laggards in the cluster and in isolation use identical feedback strategies. The following Proposition shows that this intuition is correct and allows us to consider MPEs where, in the equilibrium feedback strategies, firms condition only on the total knowledge of laggards in the cluster and in isolation.

Proposition 1 There is a set of parameter values such that, for each pattern of location choices, a Markov-perfect equilibrium $\left(X_{1}, . ., X_{n}\right)$ with the following properties exists:

- $X_{1}\left(k_{1}, . ., k_{n}\right)=\Phi_{1}\left(k_{1}, K^{C}, K^{I}\right)$,

- $X_{i}\left(k_{1}, . ., k_{n}\right)=\Phi^{C}\left(k_{i}, k_{1}, K^{C}, K^{I}\right)$ for $i=2, . ., n$ and $l_{i}=C$,

- $X_{i}\left(k_{1}, . ., k_{n}\right)=\Phi^{I}\left(k_{i}, k_{1}, K^{C}, K^{I}\right)$ for $i=2, . ., n$ and $l_{i}=I$, 
where $K^{C}=\sum_{\substack{j \in N_{C} \\ j \neq 1}} k_{j}$, and $K^{I}=\sum_{\substack{j \in N_{I} \\ j \neq 1}} k_{j}$. Under this Markov-perfect equilibrium there exists a globally stable steady state.

Proof. We show the proposition by proving that, under the assumption that all other firms follow feedback rules of the form stated in the proposition, the optimal feedback rules of the leader and of an arbitrary laggard in the cluster and in isolation also have the form stated in the proposition.

As mentioned above quantity choices do not have intertemporal effects in this model. Therefore, in a Markov-perfect equilibrium each firm chooses quantities in order to maximize its current profits given the current knowledge stock of all firms. Hence, under the assumption that all quantities are positive, which can be assured by assuming that the market size parameter $a$ is sufficiently large, standard oligopoly theory (see e.g. Vives (1999)) implies that at any point in time $t$ quantities in the MPE are given by

$$
q_{i}^{c}=\frac{a-\bar{c}+(n+1) \gamma k_{i}-\gamma \sum_{j=1}^{n} k_{j}}{b(n+1)}=\frac{a-\bar{c}+(n+1) \gamma k_{i}-\gamma\left(k_{1}+K^{C}+K^{I}\right)}{b(n+1)} .
$$

The instantaneous profit of firm 1 at time $t$ can then be written as

$$
F_{1}\left(k_{1}, K^{C}, K^{I}, x_{1}\right)=\frac{\left(a-\bar{c}+(n+1) \gamma k_{1}-\gamma\left(k_{1}+K^{C}+K^{I}\right)\right)^{2}}{b(n+1)^{2}}-\frac{\eta_{1}}{2} x_{1}^{2},
$$

whereas for any other firm $i, i=2, . ., n$ we have

$$
F_{i}\left(k_{i}, k_{1}, K^{C}, K^{I}, x_{i}\right)=\frac{\left(a-\bar{c}+(n+1) \gamma k_{i}-\gamma\left(k_{1}+K^{C}+K^{I}\right)\right)^{2}}{b(n+1)^{2}}-\frac{\eta}{2} x_{i}^{2} .
$$

Let us now first consider the dynamic optimization problem of the technological leader, firm 1. Without restriction of generality, we consider the case in which the leader locates in the cluster. The case in which the leader locates in isolation can be treated in an analogous way. Assuming that all other firms follow the stated feedback rules, the problem of firm 1 is

$$
\max _{x_{1}(.)} \int_{0}^{\infty} e^{-r t} F_{1}\left(k_{1}, K^{C}, K^{I}, x_{1}\right) d t
$$

s.t.

$$
\begin{aligned}
\dot{k}_{1} & =x_{1}+\beta K^{C}-\delta k_{1} \\
\dot{K}^{C} & =\sum_{j \in N_{C} \backslash\{1\}} \Phi^{C}\left(k_{j}, k_{1}, K^{C}, K^{I}\right)+\beta n_{C} k_{1}+\beta\left(n_{C}-1\right) K^{C}-\delta K^{C} \\
& =\left(n_{C}-1\right) \Phi^{C}\left(\frac{K^{C}}{n_{C}-1}, k_{1}, K^{C}, K^{I}\right)+\beta n_{C} k_{1}+\beta\left(n_{C}-1\right) K^{C}-\delta K^{C} \\
\dot{K}^{I} & =\sum_{j \in N_{I}} \Phi^{I}\left(k_{j}, k_{1}, K^{C}, K^{I}\right)-\delta K^{I} \\
& =\left(n-n_{C}\right) \Phi^{I}\left(\frac{K^{I}}{n-n_{C}}, k_{1}, K^{C}, K^{I}\right)-\delta K^{I} \\
k_{1}(0) & =k_{1}^{i n i}, K^{C}(0)=\sum_{j \in N_{C} \backslash\{1\}} k_{j}^{i n i}, K^{I}(0)=\sum_{j \in N_{I}} k_{j}^{i n i} .
\end{aligned}
$$


It should be noted that in some transformations above we have used the fact that feedback rules in linear-quadratic games are linear with respect to the states.

The problem of firm 1 can therefore be formulated as a dynamic optimization problem with the three-dimensional state-vector $\left(k_{1}, K^{C}, K^{I}\right) \in[0, \infty)^{3}$. Denoting the value function of the problem by $V_{1}\left(k_{1}, K^{C}, K^{I}\right)$, the Hamilton-Jacobi-Bellman Equation is given by

$$
\begin{aligned}
& r V_{1}\left(k_{1}, K^{C}, K^{I}\right)=\max _{x \in[0, \infty)}\left[F_{1}\left(k_{1}, K^{C}, K^{I}, x_{1}\right)+\frac{\partial V_{1}}{\partial k_{1}}\left(x_{1}+\beta K^{C}-\delta k_{1}\right)+\right. \\
& \quad+\frac{\partial V_{1}}{\partial K^{C}}\left(\left(n_{C}-1\right) \Phi^{C}\left(\frac{K^{C}}{n_{C}-1}, k_{1}, K^{C}, K^{I}\right)+\beta n_{C} k_{1}+\beta\left(n_{C}-1\right) k_{1}+\beta\left(n_{C}-2\right) K^{C}-\delta K^{C}\right)+ \\
& \left.\quad+\frac{\partial V_{1}}{\partial K^{I}}\left(\left(n-n_{C}\right) \Phi^{I}\left(\frac{K^{I}}{n-n_{C}}, k_{1}, K^{C}, K^{I}\right)-\delta K^{I}\right)\right]
\end{aligned}
$$

Maximizing the right hand side of Equation (9) with respect to the control variable $x_{1}$ and substituting the expression of $F_{1}\left(k_{1}, K^{C}, K^{I}, x_{1}\right)$ in (6) yields the following optimal control for firm 1:

$$
x_{1}^{*}=\frac{1}{\eta} \frac{\partial V_{1}}{\partial k_{1}} .
$$

As it is standard in the literature, we assume a quadratic value function of the following form

$$
\begin{aligned}
V_{1}= & A^{1}+B^{1} k_{1}+B_{C}^{1} K^{C}+B_{I}^{1} K^{I}+\frac{C^{1}}{2} k_{1}^{2}+\frac{C_{C C}^{1}}{2}\left(K^{C}\right)^{2}+\frac{C_{I I}^{1}}{2}\left(K^{I}\right)^{2}+ \\
& +C_{C}^{1} k_{1} K^{C}+C_{I}^{1} k_{1} K^{I}+C_{C I}^{1} K^{C} K^{I},
\end{aligned}
$$

from which we obtain that the linear feedback rule of firm 1 is

$$
\Phi^{1}\left(k_{1}, K^{C}, K^{I}\right)=\frac{1}{\eta_{1}}\left(B^{1}+C^{1} k_{1}+C_{C}^{1} K^{C}+C_{I}^{1} K^{I}\right) .
$$

Hence, the feedback rule of firm 1 has the form stated in the proposition. 
Next, we consider the dynamic optimization problem of a laggard firm $i=2, . ., n$ that is located in the cluster. Proceeding as above, we can write the optimization problem

$$
\max _{x_{i}(.)} \int_{0}^{\infty} e^{-r t} F_{i}\left(k_{i}, k_{1}, K^{C}, K^{I}, x_{i}\right) d t
$$

s.t.

$$
\begin{aligned}
\dot{k}_{i} & =x_{i}+\beta\left(k_{1}+K^{C}-k_{i}\right)-\delta k_{i} \\
\dot{k}_{1} & =\Phi^{1}\left(k_{1}, K^{C}, K^{I}\right)+\beta K^{C}-\delta k_{1} \\
\dot{K}^{C} & =x_{i}+\sum_{j \in N_{C} \backslash\{i, 1\}} \Phi^{C}\left(k_{j}, k_{1}, K^{C}, K^{I}\right)+\beta\left(n_{C}-1\right) k_{1}+\beta\left(n_{C}-2\right) K^{C}-\delta K^{C} \\
& =x_{i}+\left(n_{C}-2\right) \Phi^{C}\left(\frac{K^{C}-k_{i}}{n_{C}-2}, k_{1}, K^{C}, K^{I}\right)+\beta\left(n_{C}-1\right) k_{1}+\beta\left(n_{C}-2\right) K^{C}-\delta K^{C} \\
\dot{K}^{I} & =\sum_{j \in N_{I}} \Phi^{I}\left(k_{j}, k_{1}, K^{C}, K^{I}\right)-\delta K^{I} \\
& =\left(n-n_{C}\right) \Phi^{I}\left(\frac{K^{I}}{n-n_{C}}, k_{1}, K^{C}, K^{I}\right)-\delta K^{I} \\
k_{i}(0) & =k_{i}^{i n i}, k_{1}(0)=k_{1}^{i n i}, K^{C}(0)=\sum_{j \in N_{C} \backslash\{1\}} k_{j}^{i n i}, K^{I}(0)=\sum_{j \in N_{I}} k_{j}^{i n i} .
\end{aligned}
$$

It can be seen that the problem of a laggard firm has a four-dimensional state-vector $\left(k_{i}, k_{1}, K^{C}, K^{I}\right) \in[0, \infty)^{4}$. The reason why in addition to its own knowledge and the total knowledge stock in the cluster and in isolation the firm also has to keep track of the knowledge stock of the leader is that the R\&D investment function of the leader differs from that of all the other firms that share her location.

Denoting the value function of Problem (12) by $V^{C}\left(k_{i}, k_{1}, K^{C}, K^{I}\right)$, the Hamilton-JacobiBellman Equation is given by

$$
\begin{aligned}
r V^{C}\left(k_{i}, k_{1}, K^{C}, K^{I}\right)=\max _{x_{i} \in[0, \infty)}\left[F_{i}\left(k_{i}, k_{1}, K^{C}, K^{I}, x_{i}\right)+\frac{\partial V^{C}}{\partial k_{i}}\left(x_{i}+\beta\left(k_{1}+K^{C}-k_{i}\right)-\delta k_{i}\right)+\right. \\
+\frac{\partial V^{C}}{\partial k_{1}}\left(\Phi^{1}\left(k_{1}, K^{C}, K^{I}\right)+\beta K^{C}-\delta k_{1}\right)+ \\
\quad+\frac{\partial V^{C}}{\partial K^{C}}\left(x_{i}+\left(n_{C}-2\right) \Phi^{C}\left(\frac{K^{C}-k_{i}}{n_{C}-2}, k_{1}, K^{C}, K^{I}\right)+\beta\left(n_{C}-1\right) k_{1}+\beta\left(n_{C}-2\right) K^{C}-\delta K^{C}\right)+ \\
\left.\quad+\frac{\partial V^{C}}{\partial K^{I}}\left(\left(n-n_{C}\right) \Phi^{I}\left(\frac{K^{I}}{n-n_{C}}, k_{1}, K^{C}, K^{I}\right)-\delta K^{I}\right)\right] .
\end{aligned}
$$

Using the expression of instantaneous profits given in (7) and maximizing the right hand side of this equation with respect to the control variable $x_{i}$, yields the following optimal control for firm $i$ :

$$
x_{i}^{*}=\frac{1}{\eta}\left(\frac{\partial V^{C}}{\partial k_{i}}+\frac{\partial V^{C}}{\partial K^{C}}\right) .
$$


We again assume a quadratic value function of the form

$$
\begin{aligned}
V^{C}= & A^{C}+B^{C} k_{i}+B_{1}^{C} k_{1}+B_{C}^{C} K^{C}+B_{I}^{C} K^{I}+\frac{C^{C}}{2}\left(k_{i}\right)^{2}+\frac{C_{11}^{C}}{2}\left(k_{1}\right)^{2}+\frac{C_{C C}^{C}}{2}\left(K^{C}\right)^{2}+\frac{C_{I I}^{C}}{2}\left(K^{I}\right)^{2}+ \\
& +C_{1}^{C} k_{i} k_{1}+C_{C}^{C} k_{i} K^{C}+C_{I}^{C} k_{i} K^{I}+C_{1 C}^{C} k_{1} K^{C}+C_{1 I}^{C} k_{1} K^{I}+C_{C I}^{C} K^{C} K^{I} .
\end{aligned}
$$

Given that each laggard firm in the cluster faces Problem (12), the linear feedback rule for laggard firms in the cluster is given by

$$
\begin{aligned}
\Phi^{C}\left(k_{i}, k_{1}, K^{C}, K^{I}\right)= & \frac{1}{\eta}\left(B^{C}+B_{C}^{C}+\left(C^{C}+C_{C}^{C}\right) k_{i}+\left(C_{1}^{C}+C_{1 C}^{C}\right) k_{1}+\right. \\
& \left.+\left(C_{C}^{C}+C_{C C}^{C}\right) K^{C}+\left(C_{P}^{C}+C_{C P}^{C}\right) K^{I}\right)
\end{aligned}
$$

Analogous considerations concerning the dynamic optimization problem of a laggard firm located in isolation show that, under the assumption of a quadratic value function for firms in isolation of the form

$$
\begin{aligned}
V^{I}= & A^{I}+B^{I} k_{i}+B_{1}^{I} k_{1}+B_{C}^{I} K^{C}+B_{I}^{I} K^{I}+\frac{C^{I}}{2}\left(k_{i}\right)^{2}+\frac{C_{11}^{I}}{2}\left(k_{1}\right)^{2}+\frac{C_{C C}^{I}}{2}\left(K^{C}\right)^{2}+\frac{C_{I I}^{I}}{2}\left(K^{I}\right)^{2}+ \\
& +C_{1}^{I} k_{i} k_{1}+C_{C}^{I} k_{i} K^{C}+C_{I}^{I} k_{i} K^{I}+C_{1 C}^{I} k_{1} K^{C}+C_{1 I}^{I} k_{1} K^{I}+C_{C I}^{I} K^{C} K^{I},
\end{aligned}
$$

the optimal feedback rule reads

$$
\begin{aligned}
\Phi^{I}\left(k, k_{1}, K^{C}, K^{I}\right)= & \frac{1}{\eta}\left(B^{I}+B_{I}^{I}+\left(C^{I}+C_{I}^{I}\right) k_{i}+\left(C_{1}^{I}+C_{1 I}^{I}\right) k_{1}+\right. \\
& \left.+\left(C_{C}^{I}+C_{C I}^{I}\right) K^{C}+\left(C_{I}^{I}+C_{I I}^{I}\right) K^{I}\right) .
\end{aligned}
$$

To establish that this profile of feedback rules constitute indeed a Markov-perfect equilibrium, we still have to show that there exists a set of value function parameters such that the Hamilton-Jacobi Bellman equations, which considering the linear nature of the feedback 
functions can be written as

$$
\begin{aligned}
r V_{1}( & \left.k_{1}, K^{C}, K^{I}\right)=F_{1}\left(k_{1}, K^{C}, K^{I}, \Phi_{1}\left(k_{1}, K^{C}, K^{I}\right)\right)+\frac{\partial V_{1}}{\partial k_{1}}\left(\Phi_{1}\left(k_{1}, K^{C}, K^{I}\right)+\beta K^{C}-\delta k_{1}\right)+ \\
& +\frac{\partial V_{1}}{\partial K^{C}}\left(\Phi^{C}\left(K^{C}, k_{1}, K^{C}, K^{I}\right)+\beta n_{C} k_{1}+\beta\left(n_{C}-1\right) K^{C}-\delta K^{C}\right)+ \\
& +\frac{\partial V_{1}}{\partial K^{I}}\left(\Phi^{I}\left(K^{I}, k_{1}, K^{C}, K^{I}\right)-\delta K^{I}\right) \\
r V^{C} & \left(k_{i}, k_{1}, K^{C}, K^{I}\right)=F_{2}\left(k_{i}, k_{1}, K^{C}, K^{I}, \Phi^{C}\left(k_{i}, k_{1}, K^{C}, K^{I}\right)\right)+ \\
& +\frac{\partial V^{C}}{\partial k_{i}}\left(\Phi^{C}\left(k_{i}, k_{1}, K^{C}, K^{I}\right)+\beta\left(k_{1}+K^{C}-k_{i}\right)-\delta k_{i}\right)+ \\
& +\frac{\partial V^{C}}{\partial k_{1}}\left(\Phi_{1}\left(k_{1}, K^{C}, K^{I}\right)+\beta K^{C}-\delta k_{1}\right)+ \\
& +\frac{\partial V^{C}}{\partial K^{C}}\left(\Phi^{C}\left(K^{C}, k_{1}, K^{C}, K^{I}\right)+\beta\left(n_{C}-1\right) k_{1}+\beta\left(n_{C}-2\right) K^{C}-\delta K^{C}\right)+ \\
& +\frac{\partial V^{C}}{\partial K^{I}}\left(\Phi^{P}\left(K^{I}, k_{1}, K^{C}, K^{I}\right)-\delta K^{P}\right) \\
r V^{I} & \left(k_{i}, k_{1}, K^{C}, K^{I}\right)=F_{2}\left(k_{i}, k_{1}, K^{C}, K^{I}, \Phi^{I}\left(k_{i}, k_{1}, K^{C}, K^{I}\right)\right)+\frac{\partial V^{I}}{\partial k_{i}}\left(\Phi^{I}\left(k_{i}, k_{1}, K^{C}, K^{I}\right)-\delta k_{i}\right)+ \\
& +\frac{\partial V^{I}}{\partial k_{1}}\left(\Phi_{1}\left(k_{1}, K^{C}, K^{I}\right)+\beta K^{C}-\delta k_{1}\right)+ \\
& +\frac{\partial V^{I}}{\partial K^{C}}\left(\Phi^{C}\left(K^{C}, k_{1}, K^{C}, K^{I}\right)+\beta\left(n_{C}-1\right) k_{1}+\beta\left(n_{C}-2\right) K^{C}-\delta K^{C}\right)+ \\
& +\frac{\partial V^{I}}{\partial K^{I}}\left(\Phi^{I}\left(K^{I}, k_{1}, K^{C}, K^{I}\right)-\delta K^{I}\right)
\end{aligned}
$$

and the transversality conditions

$$
\begin{gathered}
\lim _{t \rightarrow \infty} e^{-r t} V_{1}\left(k_{1}(t), K^{C}(t), K^{I}(t)\right)=\lim _{t \rightarrow \infty} e^{-r t} V^{C}\left(k_{i}(t), k_{1}(t), K^{C}(t), K^{I}(t)\right) \\
=\lim _{t \rightarrow \infty} e^{-r t} V^{P}\left(k_{i}(t), k_{1}(t), K^{C}(t), K^{I}(t)\right)=0
\end{gathered}
$$

hold. Note that we can use the instantaneous payoff function $F_{2}$ in the formulation of the Hamilton-Jacobi Bellman equations for a laggard in the cluster and in isolation because all laggards have the same instantaneous payoff function. Inserting the expressions for the value functions (10), (14),(16), and for the feedback functions (11), (15) and (17) into the HamiltonJacobi Bellman equations and comparing coefficients of the different powers of the three (for $V_{1}$ ), respectively four (for $V^{C}$ and $V^{I}$ ), variables yields a system of 40 equations with 40 unknowns. In case the location profile is such that either no laggard is in the cluster, or no laggard is in isolation, the corresponding value function and Hamilton-Jacobi Bellman equation have to be removed from the system. In this case, the system reduces to 25 equations in 25 unknowns. In what follows, it is shown by numerical examples that for suitable parameter constellations this system has indeed a solution such that the induced dynamical system of $\left(k_{1}, K^{C}, K^{I}\right)$ has a positive stable steady state, which implies that also the transversality conditions are satisfied. 
In the numerical analysis of the following section we assume that firms always play according to a Markov-perfect equilibrium of the form described in Proposition 1. Equilibria of this form are characterized by 40 parameters regardless of the number of competitors in the industry ${ }^{10}$. Assuming identical equilibrium behavior by identical firms does not seem restrictive and is also in line with large parts of the differential game literature in Industrial Organization, which typically restricts attention to symmetric equilibria.

\section{Location Choice by a Technological Leader}

In this section we examine the incentives of the technological leader (firm 1) to locate in the industry cluster rather than in isolation. In order to do so we compare the value function of the technological leader under the Markov perfect equilibrium of the differential game when she locates in the cluster and in isolation, respectively.

In our baseline scenario we consider an industry with $n=6$ firms and the following parameter setting

$$
a=100, b=1, \gamma=0.22, \bar{c}=40, \beta=0.005, \delta=0.1, r=.05, \eta_{i}=\eta=10, i=2, . ., 6 .
$$

The value of $\eta_{1}$ determines the technological advantage of the leader, which is measured by

$$
\Delta \eta=\frac{\eta-\eta_{1}}{\eta}
$$

Although we do not calibrate our parameter values based on data from a specific industry, the parameter set above is consistent with stylized facts highlighted in the empirical literature ${ }^{11}$. The range of technological advantages we consider is $\Delta \eta \in[0,0.4]$, capturing a wide range of advantage sizes. In particular, the upper bound of $\Delta \eta=0.4$ corresponds to a scenario where the leader in the MPE has a long run market share between 0.5 and 0.67 depending on her location choice.

The initial values of the knowledge stock of the different firms are always set to their steady state values in a MPE of a version of the game where all firms are in isolation ${ }^{12}$. Intuitively, this captures the idea that the cluster is newly established at the beginning of our game $(t=0)$ and that in the past firms have not exchanged knowledge. Later in the paper, we also explore a situation in which all firms but the technological leader have no initial knowledge; i.e. a scenario in which a new market is established.

\footnotetext{
${ }^{10}$ This number is the sum of 15 parameters in the value function of a laggard in the cluster, 15 parameters in the value function of a laggard in isolation and 10 parameters in the value function of the technological leader.

${ }^{11}$ Under this parameter setting we obtain in the Markov-perfect equilibrium mark-up values of about 1.18, which is consistent with empirical observations for manufacturing sectors (see e.g. Christopoulou and Vermeulen (2008)) and an R\&D intensity of approximately 7.25\%, which is close to the values reported in Alcacer and Chung (2007).

${ }^{12}$ Note that this implies that initial conditions change as the parameters of the model are varied.
} 


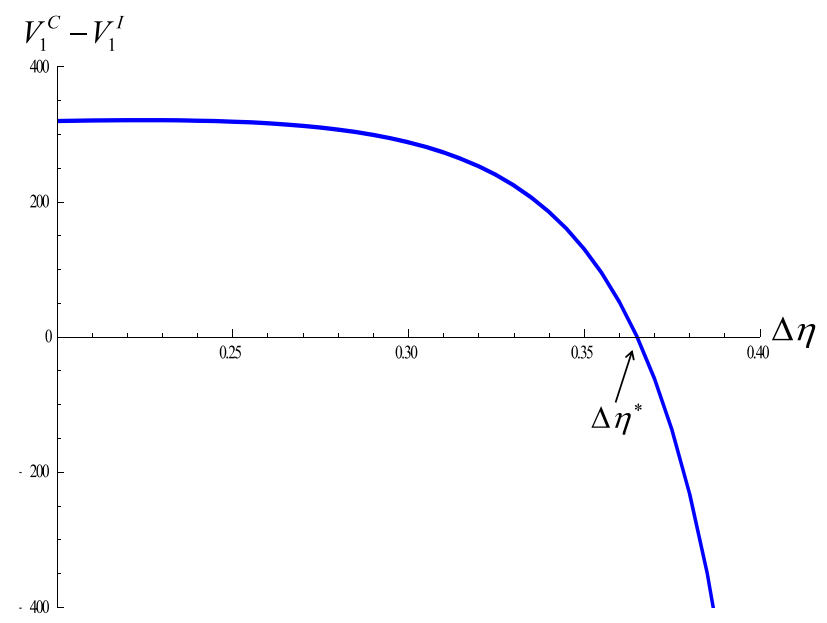

Figure 1: Difference in the value functions of the technological leader.

Before focusing on the location choice of the leader, we briefly deal with the location choices of all the other firms. In Figure 11 in the Appendix we show that, for the parameter setting considered here and for the entire range of potential technological advantages we study, any firm which has no technological advantage (i.e. the firms $i=2, . ., n$ ) - that we denote as a laggard - is better off by locating in the cluster than in isolation, no matter what the location choice of the technological leader is ${ }^{13}$. Hence, in what follows we assume that all laggards are located in the cluster. The location pattern resulting from the optimal location choice of the leader is then indeed an equilibrium of the location choice stage.

Figure 1 depicts the difference in the value functions of firm 1 between locating in the cluster and in isolation as a function of her technological advantage $(\Delta \eta)$. It can be seen that for relatively small cost advantages it is profitable for the leader to locate in the cluster. In particular, up to a cost advantage of about $30 \%$ the incentives of the leader to choose the cluster are essentially unaffected by the size of her advantage (i.e. the difference between the value functions in the two cases remains more or less constant). This picture changes dramatically for larger values of $\Delta \eta$. In particular, for a cost advantage larger than 36.5 the leader is better off by choosing to locate in isolation. We denote the threshold where her optimal location choice changes with $\Delta \eta^{*}$.

To better understand the factors behind the switch in the leader's optimal location choice, we show in Figure 2 the dynamics of the difference in the leader's instantaneous profits and knowledge stocks between the cases of location in the cluster and in isolation. This figure is drawn for $\Delta \eta=\Delta \eta^{*}$, so that the leader is indifferent between her two location choices. From

\footnotetext{
${ }^{13}$ The figures are drawn under the assumption that all other laggards are located in the cluster.
} 


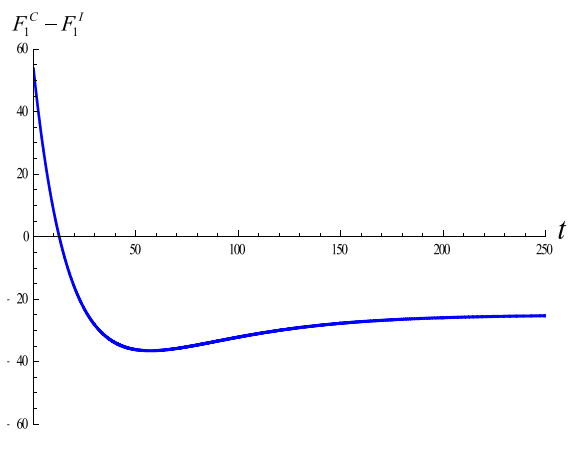

(a)

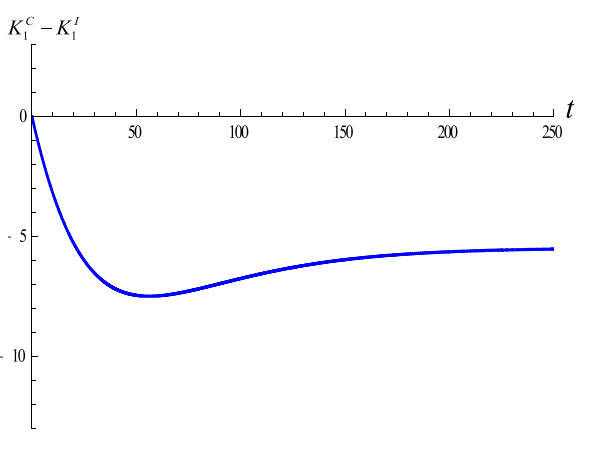

(b)

Figure 2: Difference in (a) instantaneous profits and (b) knowledge stocks of the technological leader.

panel (a) of the figure, it can be seen that initially the leader benefits substantially from locating in the cluster. This follows from the fact that she invests considerably less in R\&D when locating in the cluster compared to when she is in isolation. In a MPE, the leader anticipates that when she locates in the cluster her current $R \& D$ investments contribute to reducing the future costs of her competitors, which in turn reduces her incentives to invest. In the early periods after the location decision, the market share of the leader is hardly affected by her location choice. Therefore, the investment effect described above dominates, and firm 1 obtains a higher payoff when locating in the cluster. However, if she locates in the cluster, competitors catchup much faster in terms of knowledge, as they can exploit the stronger available spillovers ${ }^{14}$. The faster catching-up of competitors implies that the market share of the leader becomes smaller compared to the scenario in which she locates in isolation. Furthermore, a higher total knowledge stock in the industry leads to lower prices. Due to the combination of these two effects, the profits of the leader in the medium and long run are larger if she locates in isolation. In the long run, the negative implications of the cluster location for the leader both with respect to instantaneous profits and knowledge become slowly smaller over time, as these variables converge to their steady state. This is due to the slowly increasing inwards spillovers received by the leader if she is in the cluster, which stem from the laggard firms slowly increasing their $R \& D$ activities along the stable path to the steady state.

Panel (b) of Figure 2 shows that the knowledge stock of the leader is always larger when she locates in isolation. As pointed out above, the leader's investment incentives are smaller if she locates in the cluster, reflecting the strength of outwards spillovers.

\footnotetext{
${ }^{14}$ Studying the dynamics under the MPE for parameter constellations such that the advantage of the leader is small (e.g. $\Delta \eta=0.25$ ) shows that being in the cluster allows the leader to benefit from incoming spillovers to the extent that she acquires a larger long run knowledge stock advantage being in the cluster than in isolation.
} 


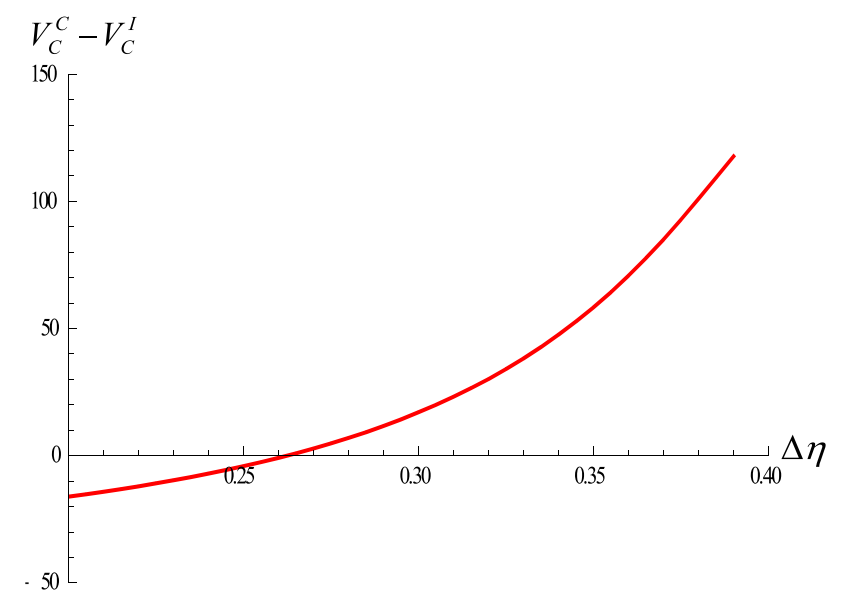

Figure 3: Difference in the value functions of the technological laggards.

We now turn to the implications of the leader's location choice on the competitors. Figure 3 depicts the difference of a competitor's value function between the case in which the leader chooses to locate in the cluster and that in which she locates in isolation. It can be seen that the competitors profit more from the leader being in the cluster the larger her technological advantage is. For small values of $\Delta \eta$, the competitors prefer that the leader locates in isolation. However, for these values of $\Delta \eta$, the leader is better off joining the cluster (see Figure 1). Conversely, for large technological advantages $\left(\Delta \eta>\Delta \eta^{*}\right)$ it would be particularly profitable for the laggards if the leader were to join the cluster, but the leader has no incentive to do so.

To grasp a better intuition of the forces at play, we again consider the dynamics of profits and knowledge of the laggard firms in Figure 4. Figure 4(b) shows that the laggards' knowledge stock is always smaller when the leader locates in isolation compared to when she joins the cluster. Furthermore, as already shown above in Figure 2(b), the (long-run) knowledge stock of the leader is larger if she locates in isolation. Together, these two observations yield higher long-run profits for the laggards when the leader locates in the cluster. Nonetheless, the laggards' R\&D investment is systematically lower if the leader locates in isolation, as they anticipate that in this scenario their market shares will be smaller. Due to the initial 'savings' stemming from this investment effect, as can be seen in Figure 4(a), in the early periods following the leader's location choice the profits of the laggards are larger if the leader locates in isolation. However, in subsequent periods, the knowledge effects highlighted above dominate and the laggards' profits become larger having the leader in the cluster ${ }^{15}$.

\footnotetext{
${ }^{15}$ As already noted when discussing the effects of location choice on the leader's knowledge stock, studying the dynamics under the MPE for parameter constellations such that the advantage of the leader is small (e.g.
} 


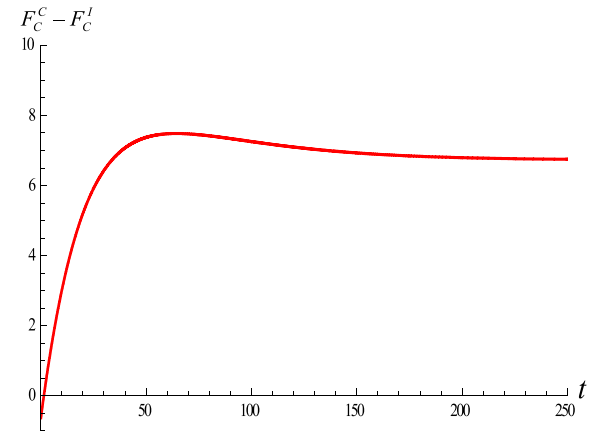

(a)

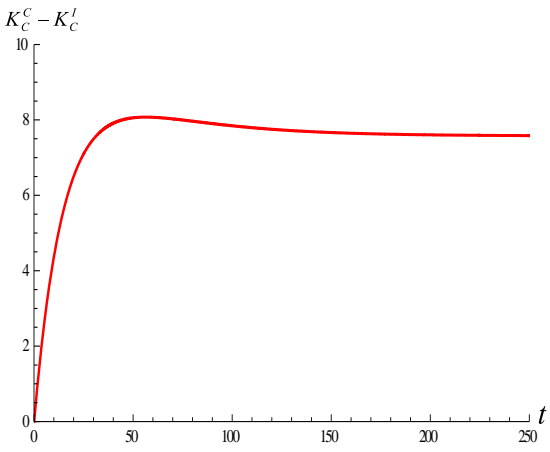

(b)

Figure 4: Difference in (a) instantaneous profits and (b) knowledge stocks of the technological laggards.

Sensitivity of the threshold $\Delta \eta^{*}$. The discussion above highlights that it is optimal for the leader to locate in isolation if and only if her technological advantage is larger than the threshold $\Delta \eta^{*}$. Therefore, it is important to understand how this threshold is affected by the key parameters of the model. Of particular interest in this respect is the behavior of $\Delta \eta^{*}$ with respect to changes in the discount rate $r$, since such an analysis allows us to understand whether myopic technological leaders are more likely to join an industrial cluster. Based on the discussion above on the dynamics of the leader's instantaneous profits, one should expect that more myopic firms have higher incentives to join the cluster. This is confirmed by Figure 5, which shows that the threshold $\Delta \eta^{*}$ is strictly increasing in $r^{16}$.

Considering next the effect of market concentration on the threshold $\Delta \eta^{*}$, we observe in Figure 6(a) that the incentives of the leader to join the cluster increase the larger is the number of competitors in the industry ${ }^{17}$. To better understand this observation note that, for given technological advantage of the leader, her knowledge stock is hardly affected by the number of firms in the industry if she locates in isolation. However, her knowledge stock is positively affected by the entry of an additional firm if she belongs to the cluster. This is due to the increased inwards spillovers in the cluster induced by the entry of the additional firm. For the $\Delta \eta=0.25)$ substantially changes the above picture. In this case, in fact, the long-run knowledge advantage of the leader is larger when she locates in the cluster, which means that the laggards achieve higher profits in the long run if the leader locates in isolation. As it is evident from Figure 3, this implies that, for sufficiently low $\Delta \eta$, the total discounted profit streams of the laggards are larger if the leader does not join the cluster.

${ }^{16}$ Although the corresponding figure is not reported here, the same arguments also explain why the threshold $\Delta \eta^{*}$ is strictly increasing in the knowledge depreciation rate $\delta$.

${ }^{17}$ Consistent with our arguments above we assume that all laggards are located in the cluster. 


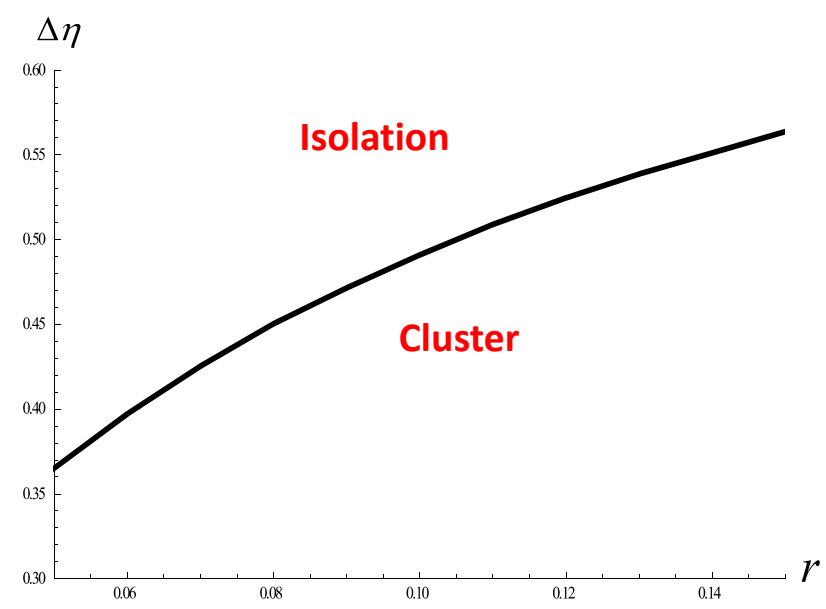

Figure 5: Sensitivity of the threshold $\Delta \eta^{*}$ with respect to the discount rate.

same reason, also the knowledge stock of the laggards becomes larger if an additional firm enters the cluster, but this increase occurs regardless of whether the leader is in the cluster or not. Overall, these effects imply that the comparison of the two location choices for the leader shifts in favor of the cluster as the number of firms in the market increases. However, the increase of the number of firms in the cluster also amplifies the costs of outwards spillovers for the leader, since additional competitors receive spillovers from her. Our numerical analysis shows that the inwards spillovers effects dominate and the leader's incentives to locate in the cluster become larger as the industry becomes less concentrated. Figure 6(a) also shows that this finding is robust with respect to variations in the discount rate of firms.

The same qualitative arguments, building on inwards versus outwards spillovers, explain the dependence of the threshold $\Delta \eta^{*}$ on the spillover intensity parameter $\beta$, as shown in Figure 6(b). Quite intuitively, increasing the parameter $\beta$ has the same implications as increasing the number of firms for generating and benefiting from inwards and outwards knowledge spillovers.

Welfare Analysis. So far, we have studied the implications of the leader's location choice for the different types of firms in the industry (i.e. the leader herself and the laggards). We now turn to the implications of location choices in terms of total industry performance and welfare. In Figure 7, we show the dynamics of the difference of these indicators between the cases in which the leader locates in the cluster and in isolation. As above, the structural advantage of the leader has been chosen as $\Delta \eta=\Delta \eta^{*}$, such that the leader is indifferent between the two options. First, it should be noted that both total industry profits and welfare are larger for all $t$ if the leader joins the cluster. Focusing on total profits, three phases can be identified (see 


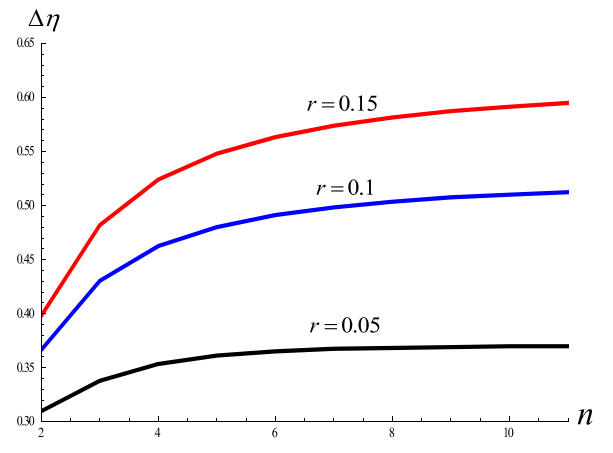

(a)

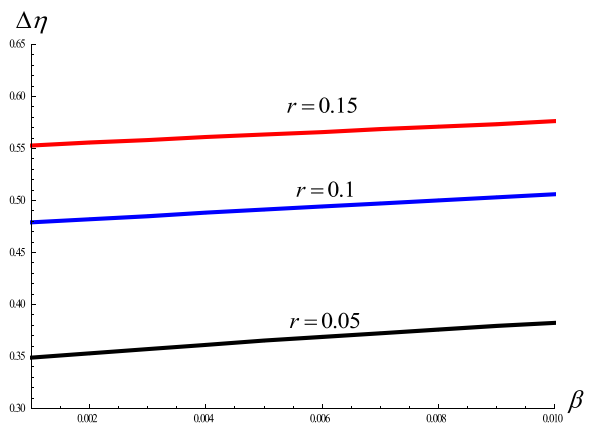

(b)

Figure 6: Sensitivity of $\Delta \eta^{*}$ with respect to (a) the number of firms and (b) spillover intensity.

panel (a) of Figure 7). Upon entering the cluster in $t=0$, the leader's investment diminishes, which increases her profits; an effect that dominates the sign of the total profit difference. The periods between $t=0$ and (approximately) $t=50$ are characterized by the catching-up of the laggards knowledge stocks. As discussed above, in this phase the leader is worse off than she would be in isolation, whereas the laggards gain relative to that case. Overall, total industry profits diminish because market shares shift from the more efficient leader to the less efficient laggards. Due to the knowledge spillovers accruing to the laggards, the sum of the marginal production costs of all competitors - that determines prices under Cournot competition - is smaller (and decreasing over time) during this period if the leader locates in the cluster. Hence, having the leader locating in the cluster induces lower prices relative to the case in which she locates in isolation. Finally, in the third phase, the adjustment of market shares is completed and the difference between the two cases is explained by the larger externality arising in the cluster if the leader locates there.

The dynamics of welfare in panel (b) of Figure 7 shows a similar pattern as total profits except for the phase up to $t=50^{18}$. This is easily explained, since the relative decrease in prices that hurts total profits increases consumer surplus. The positive consumer surplus effect dominates so that the advantage of locating in the cluster in terms of welfare increases over time. An immediate implication of this observation is that the optimal location choice of the technological leader can be inefficient. In particular, if her advantage is larger than the threshold $\Delta \eta^{*}$, it is optimal for the leader to locate in isolation, but from our discussion above it follows by continuity that welfare would be larger if the leader joins the cluster, at least for $\Delta \eta$ close to the threshold.

\footnotetext{
${ }^{18}$ We compute welfare in each period $t$ in the standard way as the utility of the representative consumer with Dixit-Stiglitz preferences minus the sum of the production costs of all firms and their R\&D investment.
} 


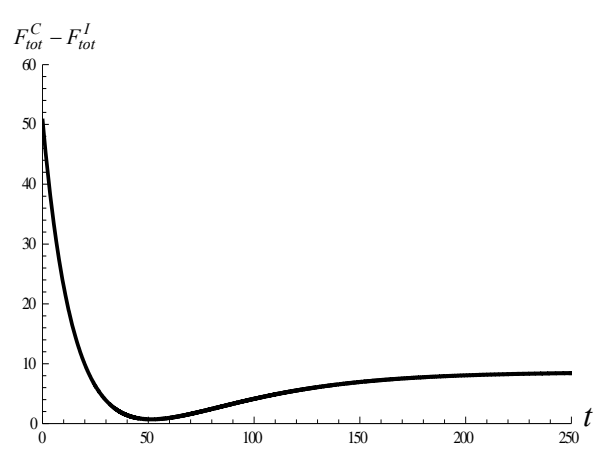

(a)

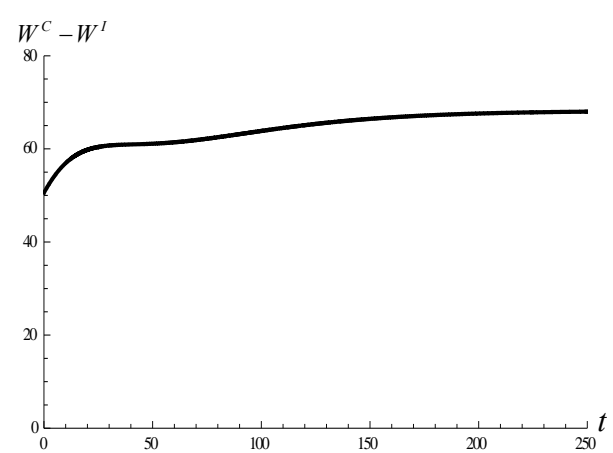

(b)

Figure 7: Difference in (a) total industry profits and (b) welfare between the technological leader locating in the cluster and in isolation.

\section{Location Choice by Market Pioneers}

So far we have been focusing on location decisions in established oligopoly markets, where technological leadership is based on a structural advantage. The leader is the firm with the highest efficiency in performing R\&D. Technological leadership can however be defined in different ways. In particular, in newly established sub-markets within an industry, leadership may be due to an initial knowledge advantage based on early entry in relevant $R \& D$ activities rather than on structural advantages. In this section, we investigate the optimal location choices of a firm having an initial rather than a structural advantage, and compare our findings with those obtained in the previous section.

In order to carry out this analysis we assume that firm 1 has the same R\&D cost parameter as all other firms in the industry (i.e. $\eta_{1}=\eta=10$ ). However, given that we want to focus on a newly established product, we assume that at $t=0$ all firms apart from firm 1 (who is again assumed to be the technological leader) have a knowledge stock of zero (i.e. $k_{i}^{i n i}=0, i=2, . ., n$ ), while firm 1 already has a positive knowledge stock $\left(k_{1}^{i n i}>0\right)$. We measure the technological advantage of the leader as her initial edge with respect to production costs relative to an arbitrary competitor $i$; i.e.

$$
\tilde{k}=\frac{c_{i}-c_{1}}{c_{i}}=\frac{\gamma k_{1}^{i n i}}{\bar{c}} .
$$

Apart from these changes all parameters are kept identical to those considered in the previous section.

It is clear from Figure 8(a) that the structure of the optimal location decision for the leader is the same as in the structural advantage case. There exists a threshold $\tilde{k}^{*}$ above which it is optimal for the leader to locate in isolation. Like in the structural advantage case, the laggards 


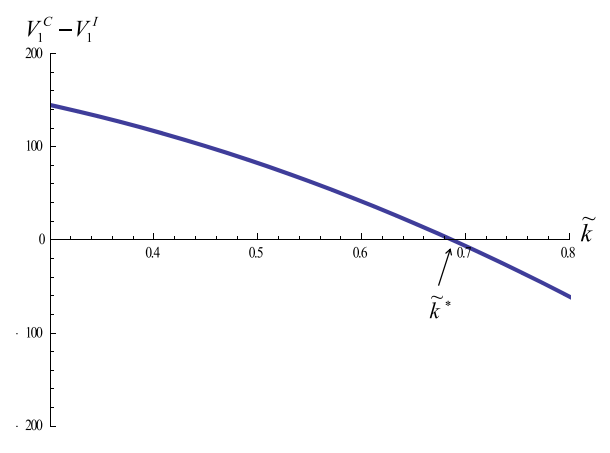

(a)

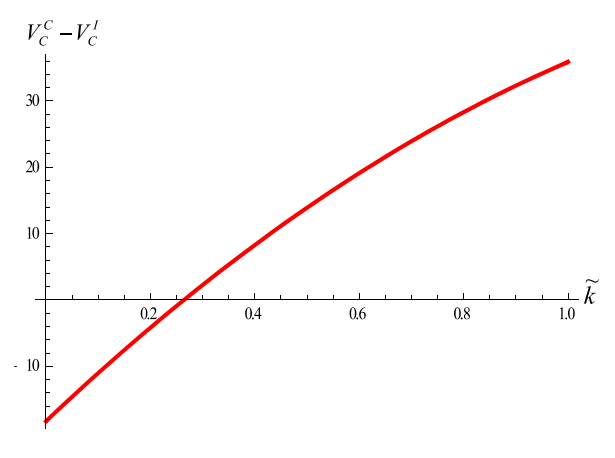

(b)

Figure 8: Difference in value functions of (a) the technological leader and (b) the laggards between the leader locating in the cluster and in isolation.

profit from the leader joining the cluster only if her advantage is sufficiently large (see Figure $8(\mathrm{~b})$ ). The positive effect of the leader joining the cluster becomes stronger the larger her initial knowledge is.

Looking again at the dynamics of differences in profits and knowledge stocks for the leader and the laggards (see Figure 9), we observe some key differences relative to the structural advantage case ${ }^{19}$. In particular, opposite to what we found in the previous section, the long run profits of the leader are now larger if she joins the cluster, while those of the laggards are larger if the leader locates in isolation. Both the leader and the laggards acquire higher long run knowledge stocks if the leader joins the cluster, but the laggards cannot transform their higher knowledge into higher profits because the leader is a much stronger competitor if she joins the cluster. Focusing next on the short run dynamics, we observe that differences in profits and knowledge exhibit qualitatively identical patterns to those discussed for the structural advantage case. This is quite intuitive since also in that case the short run dynamics is mainly driven by the initial difference in knowledge between the leader and the laggards, resulting there from the existence of structural differences.

The main qualitative difference between the cases of structural and temporary (initial) technological advantage is that in the former case the leader is better off in isolation in the long run, whereas in the latter case she profits in the long run from being part of the cluster. In the structural advantage case, the difference between outwards and inwards spillovers for the leader if she locates in the cluster is persistently larger than that for the other firms in the cluster. Loosely speaking, this means that the leader keeps 'cross-subsidizing' her competitors.

\footnotetext{
${ }^{19}$ Analogously to the analysis in the previous section, the dynamics is depicted for a technological advantage $\tilde{k}=\tilde{k}^{*}$ such that the leader is indifferent between her location options.
} 


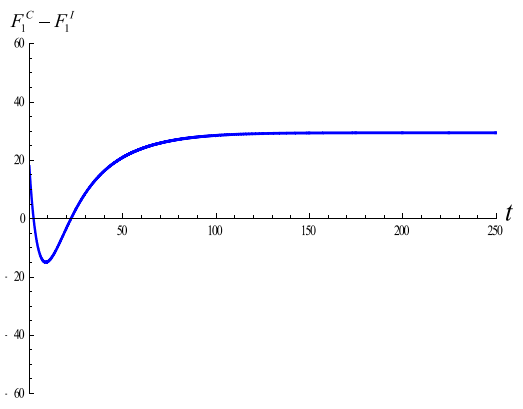

(a)

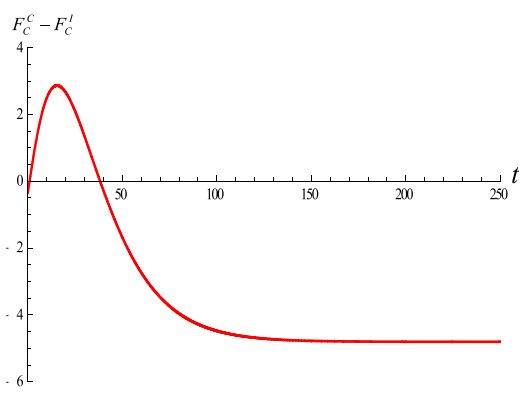

(c)

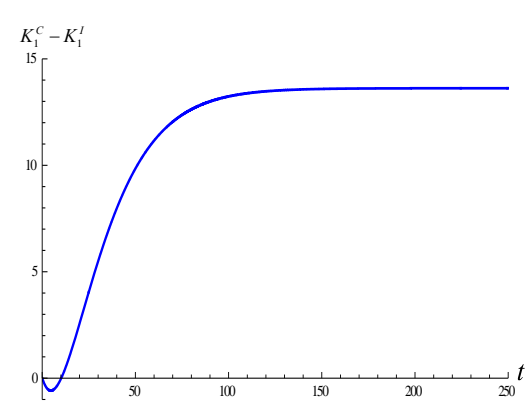

(b)

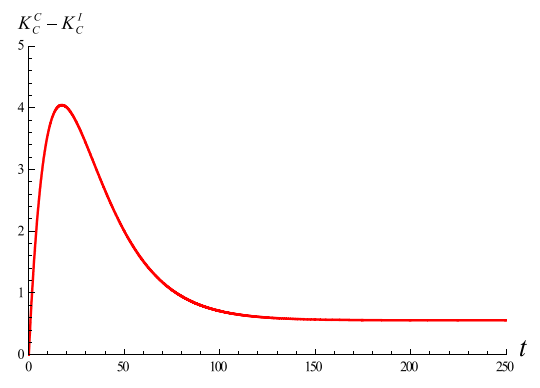

(d)

Figure 9: Difference in instantaneous profits and knowledge stocks for the technological leader ((a) and (b)) and for the technological laggards ((c) and (d)) between the leader locating in the cluster and in isolation.

Conversely, in the temporary knowledge advantage case, the net long run spillovers of the leader in the cluster are the same as those of the competitors. The leader here primarily profits from the larger externalities emerging in the cluster, which explains the different long-run dynamics in the two cases.

The discussion above immediately highlights why - opposite to what observed in the structural advantage case for the threshold $\Delta \eta^{*}$ - increasing the discount rate $r$ reduces the threshold $\tilde{k}^{*}$ beyond which the leader chooses to locate in isolation (see Figure 10). In the temporary advantage case the leader profits in the long run from the larger net spillovers emerging in the agglomeration (while the benefits of her superior initial knowledge stock are faster exhausted if she joins the cluster). Therefore, her incentives to locate in the cluster are larger the less myopic she is ${ }^{20}$. Putting this together with our findings for the structural advantage case shows that it is hard to make general statements about the relationship between the farsightedness

\footnotetext{
${ }^{20}$ The same argument also explains why the threshold $\tilde{k}^{*}$ is decreasing in the knowledge depreciation rate $\delta$, again opposite to what occurs to the threshold $\Delta \eta^{*}$ in the structural advantage case.
} 


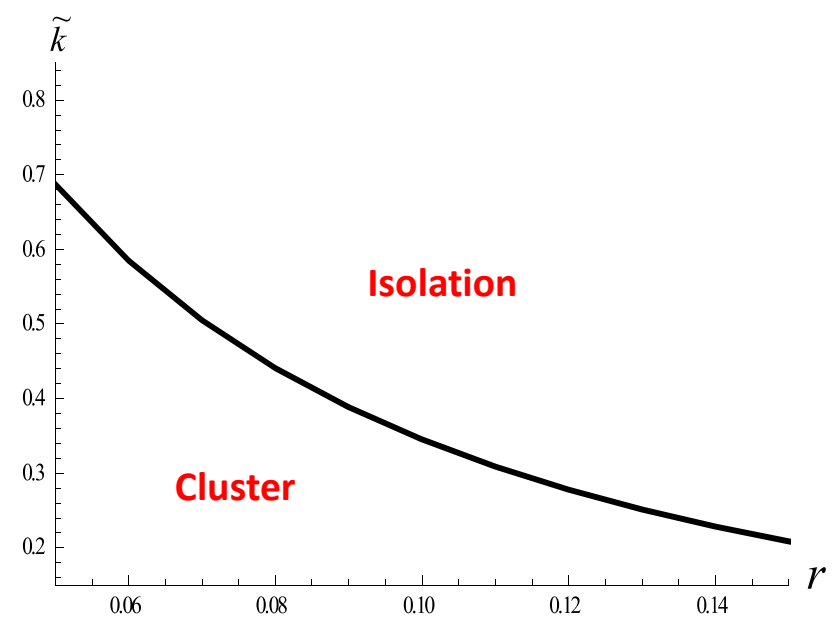

Figure 10: Sensitivity of the threshold $\tilde{k}^{*}$ with respect to the discount rate.

of a firm and its incentives to locate in an industrial cluster. Whether increased farsightedness makes locating in the cluster or in isolation more attractive depends on the type of advantage a technological leader has. Finally, the effects of changes in industry concentration and spillovers' intensity on the threshold $\tilde{k}^{*}$ depend on the relative strength of inwards and outwards spillovers exactly in the same way as already discussed for the threshold $\Delta \eta *$ in the structural advantage case, so that also $\tilde{k}^{*}$ is decreasing in market concentration and increasing in the intensity of the spillovers $^{21}$.

To conclude our discussion of the temporary initial knowledge advantage case, we mention that, as in the structural advantage case, total industry profits and welfare are positively affected by the technological leader locating in the cluster. This holds true also in cases where the advantage is so substantial that it is optimal for the leader to locate in isolation. Hence, analogously to our discussion in the previous section, for $\tilde{k}>\tilde{k}^{*}$, the optimal location choice of the leader may be inefficient from a welfare perspective. The intuitive reason is again that the intensification of competition, which is triggered by the leader joining the cluster, has a positive effect on consumers' surplus (due to lower prices), which is not taken into account by the leader in her location decision.

\section{Concluding Remarks}

In this paper, we analyze in a dynamic setting the implications of location choices of technological leaders and laggards in oligopolistic markets in the presence of technological spillovers.

\footnotetext{
${ }^{21}$ We refrain from presenting the corresponding figures here. They are available upon request.
} 
To the best of our knowledge, this is the first contribution to consider the intertemporal tradeoffs associated with such choices in a dynamic game-theoretic framework. Our analysis shows that the optimal strategy of a firm is of the 'threshold type', meaning that the firm should locate in isolation only if its technological advantage relative to its competitors is sufficiently large. The observation that the optimal location strategy is of the threshold type is very robust with respect to variations in the model parameters and with respect to the considered form of technological leadership (structural vs. initial).

In addition to the general form of the optimal strategy, we also derive a number of properties of the optimal threshold. In particular, we show that in the case of structural technological leadership a higher discount rate implies larger incentives to locate in the cluster and therefore it induces a higher threshold. Conversely, if technological leadership is based only on an initial advantage in the knowledge stock, then a higher discount rate leads to a lower threshold, implying that the firm chooses to locate in isolation for a larger range of initial knowledge advantages.

These findings are not only of theoretical interest but also generate testable empirical implications. For example, assuming that the discount rates of decision makers in owner-managed firms are smaller than in companies managed by hired employees, our findings imply that $c e-$ teris paribus one should observe more owner-managed technological leaders located in isolation than employee-managed firms. This should be particularly true for established industries, in which technological leadership is likely to be due to the structural advantages of the leader. Furthermore, also our result on the threshold being increasing in industry concentration (on both the structural and the initial advantage cases) has implications for the tendency of leaders to join clusters, which could be tested cross-sectionally.

Another robust insight of our analysis is that the overall benefits in terms of total industry profits and welfare when the leader joins the industry cluster are larger than the benefits accruing to the leader herself. Hence, a normative implication of our study is that in a welfare perspective there is the need for policies that make joining an industrial cluster more attractive for technological leaders. Measures like subsidies or tax breaks (that essentially reduce production costs in the cluster), as well as institutional arrangements aimed at fostering knowledge exchanges in clusters, have been on the regional policy agendas for years, although often a clear theoretical basis as well as a rigorous empirical evaluation of the impact of these measures is missing. Our results provide some theoretical guidance on the expected effects of such measures. Clearly, this should be accompanied with more empirical work on the effects of the relevant policy measures.

In order to highlight the main tradeoffs arising in our dynamic setting, we have kept many aspects of the model very simple. Therefore, a number of extensions of the analysis carried out here should be considered. A strong assumption in our setup is that all firms are equally able to absorb the spillovers that are generated in a cluster. There is a large literature, starting 
with Cohen and Levinthal (1989), pointing out that firms are heterogeneous in their absorptive capacity, which might depend among other factors on past and current R\&D and innovative activities of the firm. Intuitively, introducing differences in firms' absorptive capacity into our location choice framework should make joining the cluster more attractive for the leader and less attractive for the laggards compared to the scenario considered in this paper. It would therefore be important understanding to what extent our results concerning location choice remain unchanged even if absorptive capacities are taken into account.

Another issue that is worth exploring is the timing of location, respectively relocation, decisions. In this paper, we assume that all firms have to decide at $t=0$ where to locate and that they cannot relocate afterwards. In a more general setting, one would allow firms to choose their location anew at each point in time, where relocation is associated with high costs.Since each relocation of a firm implies a change in the state dynamics, formally a multi-mode differential game has to be considered to analyze such a problem, where the 'mode' of the game is at each point in time determined by the current location profile. The characterization of Markov-perfect equilibria of such games poses a substantial challenge from a technical perspective, but providing a completely dynamic strategic location choice theory would be an important contribution to the literature.

Finally, the focus of this paper is entirely on the choice of $R \& D$ location, whereas several (mainly empirical) studies look at the interplay of production and R\&D location decisions, in particular in the context of multinational enterprises. Extending the dynamic game-theoretic framework developed here to allow for the location of production being distinct from the location of R\&D might yield a number of additional testable hypotheses, which could be linked to the rich empirical literature in this area. Allowing further for the possibility that firms strategically choose multiple locations over time (as, e.g., in Alcácer et al. (2013)) to affect also the competitive conditions of the industry may add yet another interesting dimension to the problem.

\section{References}

Alcácer, J. and W. Chung (2007), 'Location Strategies and Knowledge Spillovers', Management Science, 53, 760-776.

Alcácer, J. and M. Zhao (2012), 'Local R\&D Strategies and Multilocation Firms: The role of Internal Linkages', Management Science, 58, 734-753.

Alcácer, J., Dezso, C.L. and M. Zhao (2013), 'Firm Rivalry, Knowledge Accumulation, and MNE Location Choices', Journal of International Business Studies, 44, 504-520.

Almazan, A., De Motta, A. and S. Titman (2007), 'Firm Location and the Creation and Utilization of Human Capital', Review of Economic Studies, 74, 1305-1327. 
Audretsch, D. and M. Feldman (1996), 'R\&D Spillovers and the Geography of Innovation and Production', American Economic Review, 86, 630-640.

Belderbos, R., Lykogianni, E. and R. Veugelers (2008a), 'Strategic R\&D Location in European Manufacturing Industries', Review of World Economics, 144, 183-206.

Belderbos, R., Lykogianni, E. and R. Veugelers (2008b), 'Strategic R\&D Location by Multinational Firms: Spillovers, Technology Sourcing, and Competition', Journal of Economics and Management Strategy, 17, 759-779.

Bischi, G.-I. and F. Lamantia (2012a), 'A dynamic model of oligopoly with R\&D externalities along networks. Part I', Mathematics and Computers in Simulation, 84, 51-65.

Bischi, G.-I. and F. Lamantia (2012b), 'A dynamic model of oligopoly with R\&D externalities along networks. Part II', Mathematics and Computers in Simulation, 84, 66-82.

Busse, M. and C. Hefeker (2007), 'Political risk, institutions and foreign direct investment', European Journal of Political Economy, 23, 397-415.

Christopoulou, R. and P. Vermeulen (2008), 'Markups in the Euro Area and the US over the Period 1981-2004: A Comparison of 50 Sectors', ECB Working Paper No. 856.

Cohen, W.M. and D.A. Levinthal (1989), 'Innovation and Learning: The Two Faces of R \& D', Economic Journal, 99, 569-596.

Combes, P.-P. and G. Duranton (2006), 'Labour Pooling, Labour Poaching, and Spatial Clustering', Regional Science and Urban Economics, 36, 1-28.

De Beule, F. and J.-L. Duanmu (2012), 'Locational determinants of internationalization: A firm-level analysis of Chinese and Indian acquisitions', European Management Journal, 30, 264277.

Dockner, E., Jørgensen, S., Van Long N. and G. Sorger (2000), Differential Games in Economics and Management Science, Cambridge, UK: Cambridge University Press.

Ekholm, K. and K. Hakkala (2007), 'Location of R\&D and High-Tech Production by Vertically Integrated Multinationals', Economic Journal, 117, 512-543.

Fujita, M., Krugman, P. and A.J. Venables (1999), The Spatial Economy, Cambridge, MA: MIT Press.

Fujita, M. and J.-F. Thisse (2002), Economics of Agglomeration, Cambridge, UK: Cambridge University Press.

Gersbach, H. and A. Schmutzler (1999), 'External Spillovers, Internal Spillovers and the Geography of Production and Innovation', Regional Science and Urban Economics, 29, 679-696.

Gersbach, H. and A. Schmutzler (2011), 'Foreign Direct Investment and R\&D-Offshoring', $O x$ - 
ford Economic Papers, 63, 134-157.

Glaeser, E. L. and J. E. Kohlhase (2004), 'Cities, Regions and the Decline of Transportation Costs', Regional Science, 83, 197-228.

Griliches, Z. (1992), 'The Search for R\&D Spillovers', Scandinavian Journal of Economics, 94, $29-47$.

Head, K., Ries, J. and D. Swenson (1995), 'Agglomeration Benefits and Location Choice: Evidence from Japanese Manufacturing Investments in the United States', Journal of International Economics, 38, 223-247.

Henisz, W.J. (2000), 'The Institutional Environment for Multinational Investment', Journal of Law, Economics and Organization, 16, 334-364.

Jaffe, A., Trajtenberg, M. and R. Henderson (1993), 'Geographic Localization of Knowledge Spillovers as Evidenced by Patent Citations', Quarterly Journal of Economics, 108, 577-598.

Krugman, P.R. (1991), 'Increasing Returns and Economic Geography', Journal of Political Economy, 99, 483-499.

Krugman, P. and A. Venables (1995), 'Globalization and the Inequality of Nations', Quarterly Journal of Economics, 60, 857-880.

Lee, J.Y. and E. Mansfield (1996), 'Intellectual Property Protection and US Foreign Direct Investment', Review of Economics and Statistics, 78, 181-186.

Manes, S. and P. Andrews (1994), Gates: How Microsoft's Mogul Reinvented an Industry - And Made Himself the Richest Man in America, New York: Touchstone Books.

Mariotti, S. and Piscitello, L. and S. Elia (2010), 'Spatial agglomeration of multinational enterprises: the role of information externalities and knowledge spillovers', Journal of Economic Geography, 10, 519-538.

Marshall, A. (1890), Principles of Economics, London: Macmillan.

Ottaviano, G. and J.-F. Thisse (2004), 'Agglomeration and Economic Geography', in J.V. Henderson and J.-F. Thisse (eds.) Handbook of Regional and Urban Economics, Vol. 4, Amsterdam: North Holland Press.

Petit, M.-L. and F. Sanna-Randaccio (2000), 'Endogenous R\&D and Foreign Direct Investment in International Oligopolies', International Journal of Industrial Organization, 18, 339-367.

Piga, C. and J. Poyago-Theotoky (2005), 'Endogenous R\&D Spillovers and Locational Choice', Regional Science and Urban Economics, 35, 127-139.

Saxenian, A. (1994), Regional Advantage: Culture and Competition in Silicon Valley and Route 128. Cambridge: Harvard University Press. 
UNCTAD (2005), World Investment Report: Transnational Corporations and the Internationalization of R\&D, New York and Geneva: United Nations Publications.

Vives, X. (2001), Oligopoly Pricing: Old Ideas and New Tools, Cambridge, MA: MIT Press.

\section{Appendix}

\section{Optimal location choice of laggards}

Figure 11 shows the value function of a laggard firm locating in the cluster (red line) and in isolation (green line) when the technological leader locates in (a) the cluster and (b) in isolation. The two panels of the figure are drawn under the assumption that all other laggards locate in the cluster. The value function of the laggard is higher in the cluster than in isolation regardless of the value of the technological advantage $\Delta \eta$ of the leader. This observation holds true both if the leader is in or out of the cluster. Therefore, no matter what the optimal location choice of the leader is, the corresponding location profile in which all laggards firms locate in the cluster is an equilibrium of the location choice stage.

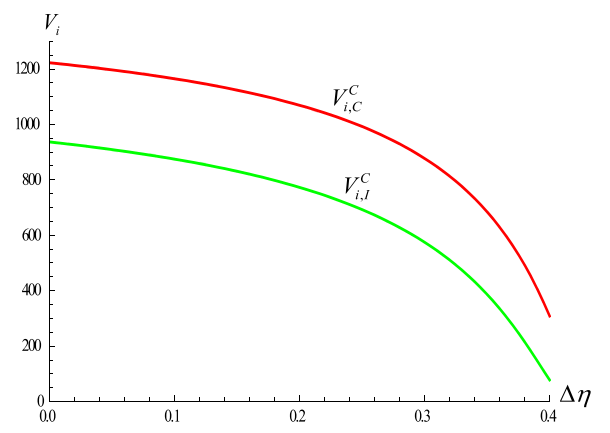

(a)

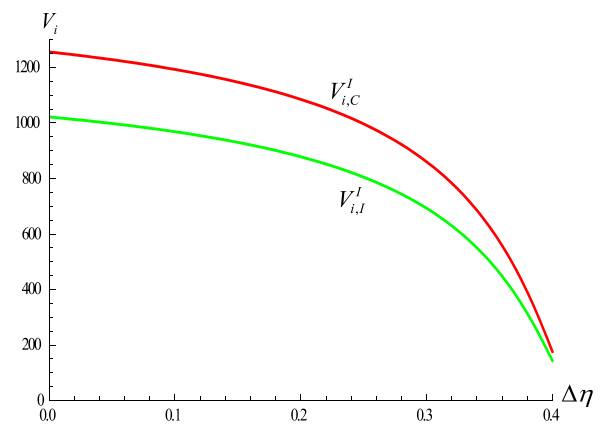

(b)

Figure 11: Value function of a laggard firm locating in the cluster (red line) and in isolation (green line) when the technological leader locates (a) in the cluster and (b) in isolation. 
1. L. Colombo, H. Dawid, Strategic Location Choice under Dynamic Oligopolistic Competition and Spillovers, Novembre 2013. 